\title{
5G Coupler Design for Intelligent Transportation System (ITS) Application
}

\author{
Dyg Norkhairunnisa Abang Zaidel ${ }^{1}$, Norhudah Seman ${ }^{2}$, Mohd Ridhuan Mohd Sharip ${ }^{3}$, \\ Dyg Azra Awang Mat ${ }^{4}$, Nur Alia Athirah Mohtadzar ${ }^{5}$ \\ 1,3,4,5 Department of Electrical and Electronic Engineering, Faculty of Engineering, Universiti Malaysia Sarawak, 94300 \\ Kota Samarahan, Sarawak, Malaysia \\ ${ }^{2}$ Wireless Communication Centre (WCC), Faculty of Electrical Engineering, Universiti Teknologi Malaysia, 81310 Johor \\ Bahru, Johor, Malaysia
}

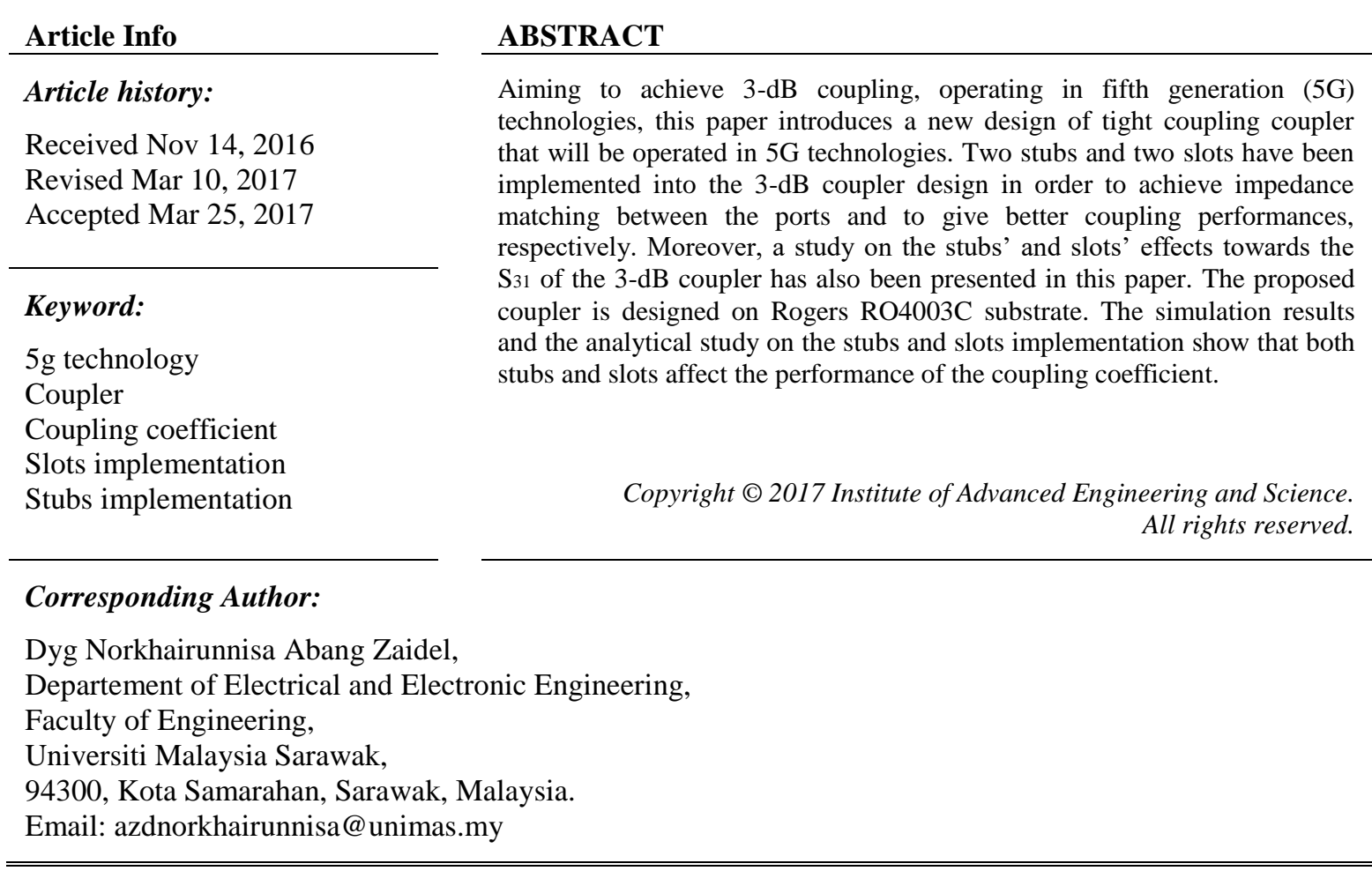

\section{INTRODUCTION}

Recently, fifth generation (5G) mobile technology has been introduced, which expected to be deployed in year 2020 [1]. As it is still considered as a new technology, few encounters need to be attended in order to change from fourth generation (4G) technology to 5G [2-3]. These include the security for the system, limitation in the frequency spectrum resources, the choice among various wireless system, network infrastructure and QoS support, jamming and spoofing and last but not least, the multi-mode user terminals [4-5]. Few advantages of having 5G technologies in our lives such as this technology will provide better coverage, higher speed and enhanced spectral efficiency. In addition to the challenges mentioned above, limited resources and also lack of new designs have been noted in $5 \mathrm{G}$ technologies. This includes antenna and passive devices.

One of the most suitable applications for 5G technology is Intelligent Transportation System (ITS). However, due to $5 \mathrm{G}$ short-range, limited space can be covered during the transmission of the data. One way to overcome the problem is by using beam-forming system where by implementing beamforming system into 5G technology the range can be widen. One of the mostly used beamforming system is Butler Matrix [6]. Basically, Butler Matrix is an $\mathrm{N} \times \mathrm{N}$ network, where the $\mathrm{N}$ indicates the inputs and outputs of the network. By using Butler Matrix, it will be easy to produce various beams in different directions. Henceforth, those beams 
can be used to provide a fast discrete electronic scanning of the antenna pattern when connected with the adaptive control unit in the antenna system [7].

By connecting $\mathrm{N} \times \mathrm{N}$ Butler Matrix to $\mathrm{N}$-elements of array antenna, switched beam antenna system, which will be pointed at different angles and generate the orthogonal beams [8]. The development of the standard Butler Matrix composed of three main components which are, $45^{\circ}$ phase shifters, crossovers and last but not least, 3-dB couplers [9-10]. When one of the Butler Matrix input was fed with signal, the output signal will have equal magnitudes and progressive phase shift between adjacent ports. Thus, different direction of radiation's beams can be formed when feeding the signal from different ports [11]. By constructing Butler Matrix into cascading side-by-side, short range and long-range radiation can be produced.

The combination of usage for short-range and long-range application at the same time for vehicle applications can successfully been done due to the development of CALM or known as a Continuous AirInterface for Long and Medium range telecommunication [12]. CALM's concept can be employed into the Intelligent Transportation System (ITS) applications. ITS application can be accessed through more than one communication systems. When ITS application system is organized into a network, it can be a very powerful platform in sensing and avoiding collision. Up to date, CALM has been introduced widely in order to offer a wide area communications to support the ITS applications. ITS application can be seen to be functioning very well on a variety of network platforms, which includes the millimeter-wave and short-range technologies like wireless fidelity (Wi-Fi), Second Generation technology (2G), 3G technology, mobile communication, 4G technology, satellite, infrared and Worldwide Interoperability for Microwave Access (WiMAX) [13].

The main advantage of ITS system is that it has a great potential in providing a direct exchange messages between vehicles related to their speed, location, position and acceleration. Furthermore, emergency situations such as the presence of ice on the road, fog, animals and accident occurred nearby could also be send through this system. In addition to that, this system could also provide the driver with all of the information even though there is no information related to weather forecasts or traffic conditions [14]. Thus, due to its attractive main advantage, arousing of demand in Intelligent Transportation System (ITS) especially in vehicle communication system applications. Therefore, it can be realized by the implementation of this promising candidate of beam forming system that produces multiple beams.

Therefore, this paper aims to develop a new design of $5 \mathrm{G}$ coupler, which is one of the main components to build the 5G Butler Matrix. $15 \mathrm{GHz}$ has been chosen in this study as an initial study for 5G technology. In the next section, the method on how the proposed designed coupler initiated is introduced. The configuration is practically approximately similar with a basic branch line coupler with $\lambda / 4$ length with additional stub and slot. The design of the $5 \mathrm{G}$ coupler is designed by using CST Microwave Studio software version 2016. The proposed coupler is designed onto Rogers RO4003C. The analysis of the parametric study of the stubs and slots is explained in Section 3. The simulation results show that the designed 5G coupler achieves a good performance for application in $5 \mathrm{G}$ technologies.

\section{5G COUPLER DESIGN}

Figure 1 and Figure 2 describe the proposed 5G coupler design both in top view and bottom view, respectively. As seen in Figure 3, two stubs have been implemented to the coupler which located between Port 1 and 2 and also between Port 3 and 4. The proposed coupler configuration is observed to be approximately similar with a basic branch line coupler with $\lambda / 4$ length. However, as shown in Figure 3, additional stub and also additional slot has been introduced in the design. The stubs are located at the top layer, as seen in Figure 1. Meanwhile, the slot is located at the ground plane, as seen in Figure 2. The use of the stub is to improve the impedance matching between these ports. Besides, the stubs have also being an important role to reduce the size of the coupler. The slot is implemented into the design to provide impedance matching along the ports, Port 1 and 2 and also Port 3 and 4.

Table 1. Dimension of the Proposed Coupler's Parameter

\begin{tabular}{cc}
\hline Parameter & Dimension $(\mathrm{mm})$ \\
\hline $\mathrm{W}$ & 24 \\
$L$ & 33.5 \\
$w f$ & 1.1 \\
$s l$ & 2.4 \\
$s w$ & 2 \\
$b l l$ & 8.8 \\
blw & 10 \\
slot_l & 9 \\
slot_w & 0.75 \\
\hline
\end{tabular}


The design of the $5 \mathrm{G}$ coupler is initiated by using simple mathematical formula based on the conventional branch line coupler [15]. Subsequently, the method and mathematical equation on the implementation of stub and slot is employed. Table 1 lists the optimized dimension of all the coupler's parameters as shown in Figure 1 and Figure 2.

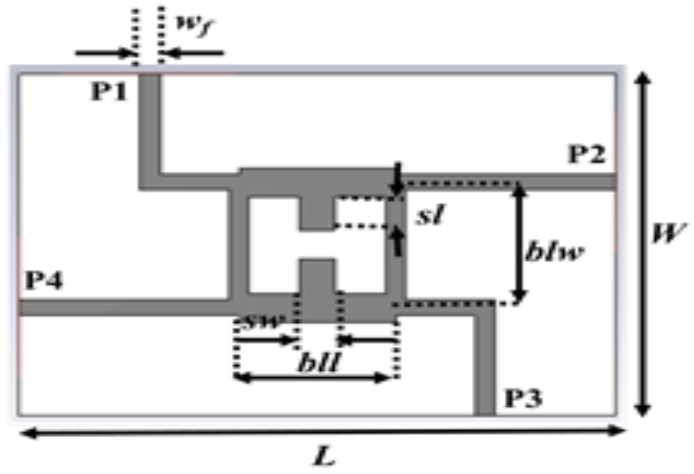

Figure 1. The proposed design of $5 \mathrm{G}$ coupler (top view)

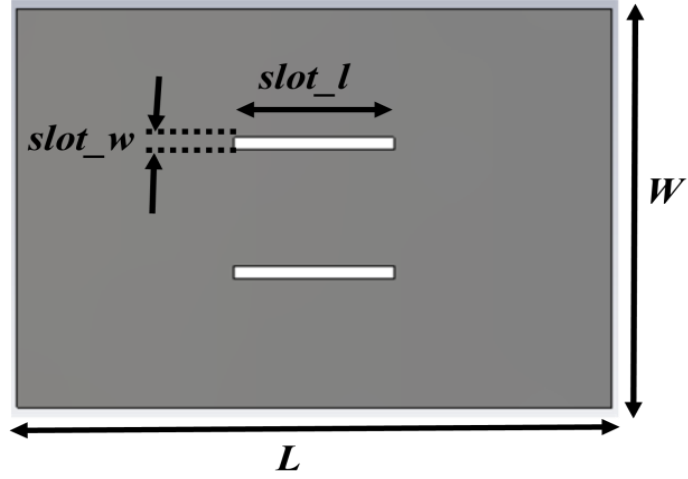

Figure 2. The proposed design of $5 \mathrm{G}$ coupler (bottom view, ground plane)

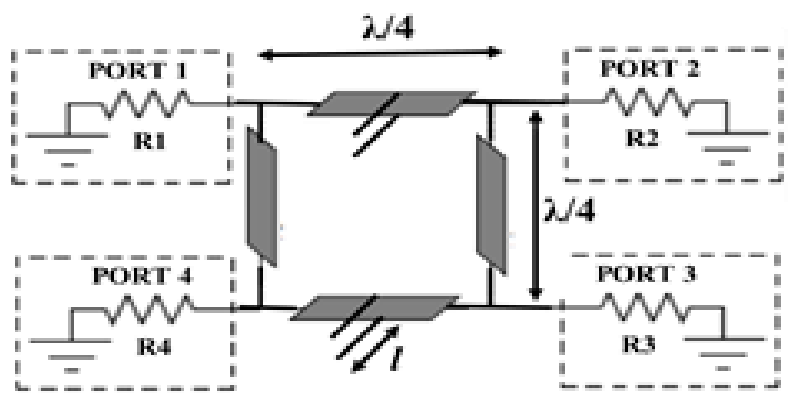

Figure 3. Circuit diagram of the proposed $5 \mathrm{G}$ coupler design

\section{ANALYSIS OF $S_{31}$ TRANSMISSION COEFFICIENT}

For the analysis of the proposed coupler on regards of the transmission coefficient performances of $\mathrm{S}_{31}$, parameters for the stub's length and also the slot's width; sl and slot_w were varied accordingly. The results are divided into two analysis for clearer observation. Figure 4 and Figure 5 demonstrate the results analysis of the proposed $5 \mathrm{G}$ coupler for both different cases as follows.

\subsection{Analysis 1: Different Stub's Length, $s l$}

For the first analysis, the value for $s l$ is varied from $1.1 \mathrm{~mm}$ to $3.1 \mathrm{~mm}$. The variation steps of the analysis is $0.7 \mathrm{~mm}$. From Figure 3, it can be observed that the best value of $\mathrm{S}_{31}$ occurred when the value of $s l$ is at $3.1 \mathrm{~mm}$.

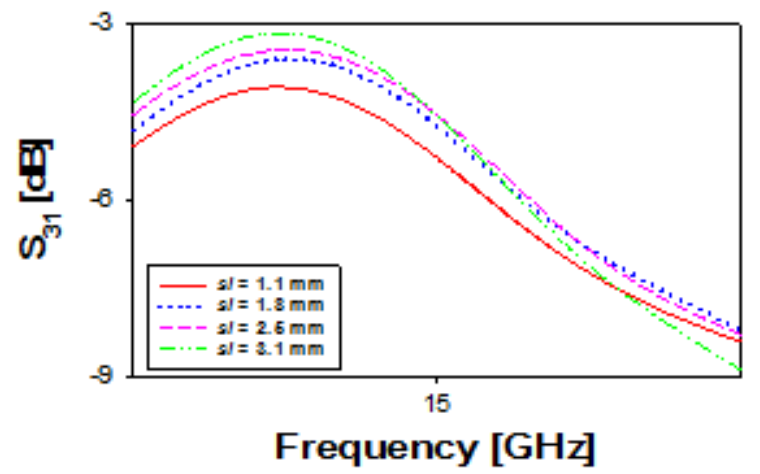

Figure 4. Coupling coefficient $\left(\mathrm{S}_{31}\right)$ for $5 \mathrm{G}$ coupler for different value of $s l$ 


\subsection{Analysis 2: Different Slot's Width, slot w}

Meanwhile, for the second analysis, the value for slot_w is varied from $0 \mathrm{~mm}$, where there is no slot available in the design then followed by $1.5 \mathrm{~mm}$ to $5.5 \mathrm{~mm}$ with variation steps of $2 \mathrm{~mm}$. From Figure 4, it can be seen that the best $\mathrm{S}_{31}$ occurred when the value of slot_w is at $1.5 \mathrm{~mm}$. However, when there is no slot implemented into the design, it can be noticed in Figure 5 that the performance of the coupling coefficient of the $5 \mathrm{G}$ coupler has been deteriorated.

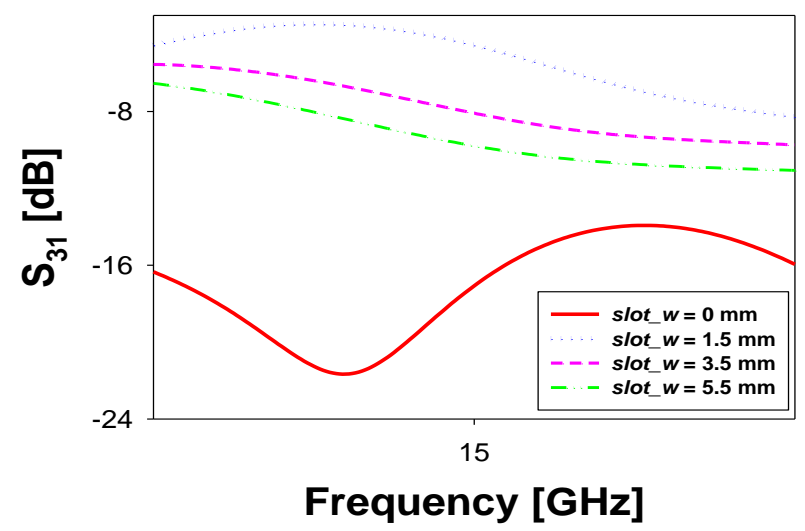

Figure 5. Coupling coefficient $\left(\mathrm{S}_{31}\right)$ for $5 \mathrm{G}$ coupler for different value of slot_w

From both analysis, it can be concluded that the introduction of the stub's and the slot's acquaintance have help in improving the coupling coefficient of the proposed coupler. As seen in Figure 5, when the slots have not been implemented into the design, the coupling coefficient of the 5G coupler's performance has been deteriorated. This situation happened due to the impedance matching towards the line from Port 1 to Port 2 and also Port 3 to Port 4 that have the stubs have been disturbed.

\section{RESULTS AND DISCUSSIONS}

Figure 6 and Figure 7 illustrate the simulated performance of the proposed $5 \mathrm{G}$ coupler in terms of Sparameters and phase difference, respectively. From the results, the bandwidth of the proposed 5G coupler is approximately $0.9 \mathrm{GHz}$ covering from 14.3 up to $15.2 \mathrm{GHz}$. Across the stated operating frequency, the optimal $\mathrm{S}_{11}$ and $\mathrm{S}_{41}$ are better than $21.6 \mathrm{~dB}$ and $25 \mathrm{~dB}$, respectively. Meanwhile, the optimal transmission coefficient of $S_{21}$ and $S_{31}$ are $-4.3 \mathrm{~dB}$ and $-3.4 \mathrm{~dB}$, respectively. For the phase difference as depicted in Figure 7 , the best phase difference performance along the operating frequency is at $-90.7^{\circ}$. Table 2 includes the optimal results plotted in Figure 6 and Figure 7. It can be concluded that, based from these figures and Table 2, the proposed coupler exhibit good performance and can be used in 5G ITS application.

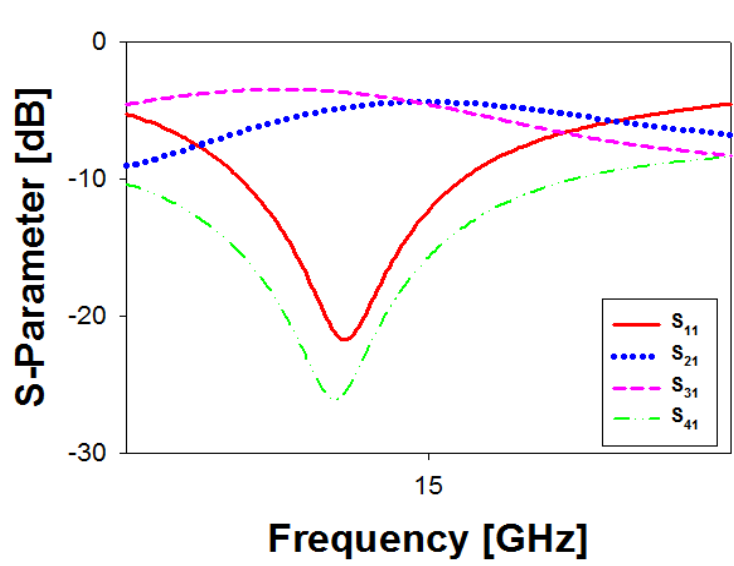

Figure 6. Simulated S-Parameter performances of the proposed $5 \mathrm{G}$ coupler

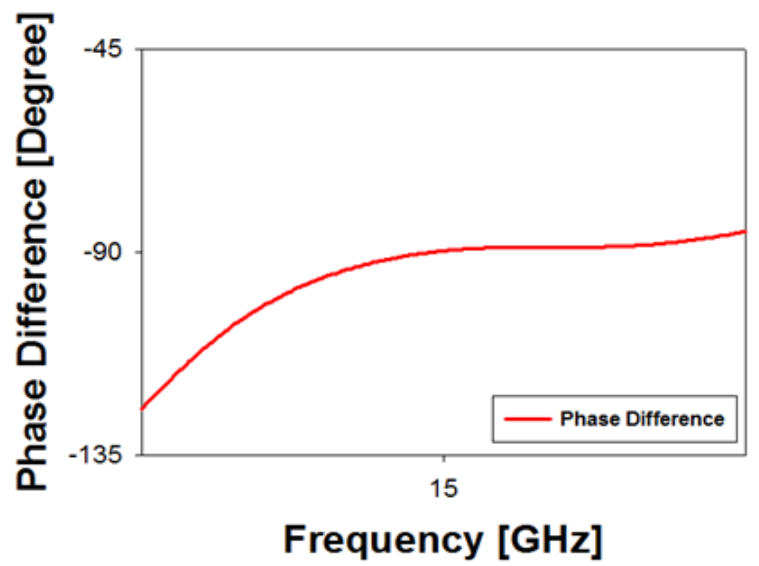

Figure 7. Simulated phase difference performance of the proposed $5 \mathrm{G}$ coupler 
Table 2. Summary of the Best/Optimal Performance of the 5G Coupler Across the Operating Frequency (14.3 GHz to $15.2 \mathrm{GHz})$.

\begin{tabular}{cc}
\hline Parameter & Performance \\
\hline $\mathrm{S}_{11}$ & $-21.6 \mathrm{~dB}$ \\
$\mathrm{~S}_{21}$ & $-4.3 \mathrm{~dB}$ \\
$\mathrm{~S}_{31}$ & $-3.4 \mathrm{~dB}$ \\
$\mathrm{~S}_{41}$ & $-25 \mathrm{~dB}$ \\
Bandwidth & $0.9 \mathrm{GHz}$ \\
Phase Difference & $-90.7^{\circ}$ \\
\hline
\end{tabular}

\section{CONCLUSION}

A new design of tight coupling coupler operating at 5G frequency range is introduced in this paper. The proposed designed implemented two stubs and two slots in order to achieve impedance matching between the ports and to give better coupling performances, respectively. In addition, an investigation on the effect of stubs and the slots towards coupling coefficient of the designed coupler has also been presented. The results of the investigation show that the coupling coefficient of the $5 \mathrm{G}$ coupler is deteriorated when there is no slots implemented into the design. This situation happened due to the impedance matching from Port 1 to Port 2 and Port 3 to Port 4 have been disturbed by the existing of the stubs. The scattering parameter and phase difference of the proposed designed coupler show good performance in the respective band. Therefore, the coupler is suitable to be used to construct a Butler Matrix for Intelligent Transportation System (ITS) applications.

\section{ACKNOWLEDGEMENTS}

This project is funded and supported by UNIMAS MyRA Special Short Term Grant with Vot Number: F02/SpSTG/1373/16/15 and Flagship Grant with Vot Number: 03G41 and 4J212.

\section{REFERENCES}

[1] R. G. S. Rao and R. Sai, "5G Introduction and Future of Mobile Broadband Communication Redefined," International Journal of Electronics, Communication \& Instrumentation Engineering Research and Development (IJECIERD), vol/issue: 3(4), pp. 119-124, 2013.

[2] S. K. Routray and K. P. Sharmila, "4.5G: A Milestone along the Road to 5G," International Conference on Information Communication and Embedded System (ICICES2016), pp. 1-6, 2016.

[3] P. Pirinen, "A Brief Overview of 5G Research Activities," 1st International Conference on 5G for Ubiquitous Connectivity (5GU), pp. 17-22, 2014.

[4] A. Gohil, et al., "5G Technology of Mobile Communication: A Survey," IEEE International Conference on Intelligent Systems and Signal Processing (ISSP), pp. 288-292, 2013.

[5] C. Felita, "5G Key Technologies: Identifying Innovation Opportunity,” IEEE International Conference on Quality in Research (QiR), pp. 235-238, 2013

[6] W. C. Lee, et al., "A compact switched beam-forming network using silicon IPD technology for low-cost 5G communication," 2016 IEEE MTT-S International Microwave Symposium (IMS), pp. 1-3, 2016.

[7] T. A. Denidni and T. E. Libar, "Wide Band Four-port Butler Matrix for Switched Multibeam Antenna Arrays", 14th IEEE Proceedings on Personal, Indoor and Mobile Radio Communications (PIMRC)," pp. 2461-2464, 2003.

[8] H. Ren, et al., "A Novel Design of 4X4 Butler Matrix with Relatively Flexible Phase Differences," IEEE Antennas and Wireless Propagation Letters, vol. 15, pp. 1277-1280, 2016.

[9] Q. L. Yang, et al., "SIW Multibeam Array for 5G Mobile Devices," IEEE Access, pp. 2788-2796, 2016.

[10] S. Sivasundarapandian, "Performance Analysis of Multi-band Multiple Beamforming Butler Matrix for Smart Antenna Systems," International Conference on Robotics, Automation, Control and Embedded Systems (RACE 2015), pp. 1-5, 2015.

[11] M. E. Bialkowski, et al., "Design of Fully Integrated 4x4 and 8x8 Butler Matrices in Microstrip/slot Technology for Ultra Wideband Smart Antennas," IEEE Antennas and Propagation Society International Symposium (AP-S 2008). pp. 1-4, 2008.

[12] N. Wall., ITS Comms., "The CALM and Efficient Way," Traffic Engineering \& Control Magazine, 2006.

[13] ITU-T Technology Watch Report 1, "Intelligent Transport Systems and CALM," 2007.

[14] S. K. A. Rahim and P. Gardner, "Adaptive Antenna System Using Cascaded Butler Matrices," International Conference on Information Communications and Signal Processing, pp. 1-4, 2007.

[15] D. M. Pozar, "Microwave Engineering," 3rd ed., J. Wiley \& Sons, 2005. 


\section{BIOGRAPHIES OF AUTHORS}
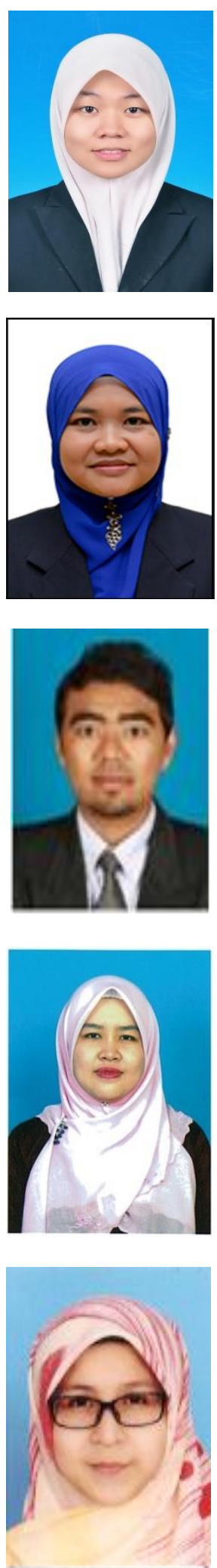

Dyg Norkhairunnisa Abang Zaidel received her B.Eng. in Electrical Engineering (Telecommunications) degree from Universiti Teknologi Malaysia, Johor, Malaysia, in 2010. She completed her PhD degree in the same university in 2014. She is now currently a Senior Lecturer in Universiti Malaysia Sarawak. Her research interests include microwave devices and smart antenna beam forming system.

Norhudah Seman received the B.Eng. in Electrical Engineering (Telecommunications) degree from the Universiti Teknologi Malaysia, Johor, Malaysia, in 2003 and M.Eng. degree in RF/Microwave Communications from The University of Queensland, Brisbane, St. Lucia, Qld., Australia, in 2005. In September 2009, she completed her Ph.D. degree at The University of Queensland. In 2003, she was an Engineer with Motorola Technology, Penang, Malaysia, where she was involved with the RF and microwave components design and testing. Currently, she is a Senior Lecturer in Wireless Communication Centre (WCC), Universiti Teknologi Malaysia. Her research interests concern the design of microwave circuits for biomedical and industrial applications, UWB technologies, and mobile communications.

Mohd Ridhuan Mohd Sharip was born in Kelantan, Malaysia in 1989. He received the B.Eng. degree from the Universiti Teknologi Malaysia, Johor, Malaysia in 2012. In 2014, he completed his M.Eng. degree at Universiti Teknologi Malaysia, Johor, Malaysia. Once graduated his B.Eng in 2012, he started his career as Maintenance Engineer at GG Circuit Sdn Bhd in Tampoi, Johor, Malaysia where he was involved in electrical and mechanical equipment. Currently, he is a Lecturer at the Universiti Malaysia Sarawak, Kuching, Malaysia. His research interests is dielectrics, nanocomposite, high voltage and power system analysis.

Dr Dayang Azra Awang Mat has received her Doctor of Engineering (Electronics) from Kyushu University, Japan in 2014. She is currently a Senior Lecturer in Universiti Malaysia Sarawak. She received her MEng. (Computer and Communication) from Universiti Kebangsaan Malaysia, Malaysia in 2006 and BEng. (Hons.) Electronic and Telecommunication from Universiti Malaysia Sarawak, Malaysia in 2002. Her research interest is in microwave and millimeter wave filter/antenna design.

Nur Alia Athirah Binti Hj Mohtadzar received the M.Eng in Advanced Electrical, Electronic \& Computer Systems from the Ritsumeikan University, Japan in 2015, with a graduation project on Wireless Body Area Network System. Since May 2015, she has been working as a lecturer in Universiti Malaysia Sarawak (UNIMAS). Her research interests include wireless network, sensing system, wearable sensors and biomedical applications. The aim is to develop system and services to improve people health by broadening the efficacy of health monitoring system, the quality of medical applied devices and the care of patients. 